\title{
Direito À SaÚde: DA (IN)EFEtiVl- DADE DAS POLITICAS PÚBLICAS À SUA JUDICIALIZAÇÃO COMO FORMA DE GARANTIR O MÍNIMO EXISTENCIAL
}

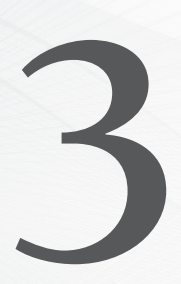

\section{Kátia Cristine Santos de Oliveira}

Mestre e Doutoranda em Direito das Relações Sociais pela PUC-SP. Professora do Curso de Direito na Universidade Tiradentes - Unit (Aracajú/SE). Professora de Direito Previdenciário da Pós-graduação na mesma instituição e na Escola da Magistratura do Trabalho - Esmatra (Pernambuco). Pesquisadora do Núcleo de Pós-graduação em Direito da Unit - Universidade Tiradentes. Advogada.

\section{Jamille Coutinho Costa}

Graduanda do 6. Período de Direito e Pesquisadora bolsista Probic pela Universidade Tiradentes - Unit.

ÁreA do DIREITO: Constitucional

Recebido em: 11.10.2011

Aprovado em: 24.10.2011

Resumo: 0 presente artigo introduz o leitor nas discussões sobre o Direito Fundamental Social à Saúde e busca analisar os vinculos entre acesso à justiça e a efetividade. Inicialmente trata do Direito Fundamental à Saúde, fazendo uma análise histórica da origem e classificação dos Direitos Fundamentais, e aborda o Direito à Saúde como dependente das políticas públicas. Faz uma análise dos recursos públicos, bem como da reserva do possivel para garantia de implementação das politicas públicas. Observa ainda o limite do judiciário e sua atuação no controle das políticas públicas, a chamada judicialização da saúde. Além disso, analisamos o mínimo exis-
ABSTRACT: This article introduces the reader in discussions on the Fundamental Right of Health and Social aims at analyzing the links between access to justice and effectiveness. Initially addresses the Fundamental Right to Health, making an analysis story of the origin and classification of Fundamental Rights, and addresses the right to health as dependent on political socials. Makes analysis of public funds along the reservation as possible to ensure implementation of policies public. Observe the limit of the judiciary and its role in the control of social policies, call the legalization of health. And the minimum existential brings as a guide 
tencial como elemento norteador das políticas de saúde, já que o principal desafio é formular estratégias políticas e sociais juntamente com outros mecanismos e instrumentos de garantia democrática, que aperfeiçoem os sistemas de saúde e de justiça com vistas à efetividade do Direito à Saúde.

Palavras-chave: Direito à Saúde - Acesso à Justiça - Mínimo existencial. element of welfare policies, jack the main challenge is to formulate political and social strategies in conjunction with other mechanisms and instruments of democratic security, to improve their health systems and justice in order to effectiveness of the Right to Health.

KEYWORDS: Right to Health - Access to Justice Existential minimum.

SumÁrio: 1. Apresentação - 2. 0 Direito Fundamental à Saúde e a sua efetividade: 2.1 Breves considerações sobre a classificação dos Direitos Fundamentais; 2.20 Direito à Saúde como Direito Fundamental Social; 2.3 A efetividade do Direito Fundamental à Saúde, políticas públicas e seus limites; 2.40 Direito Fundamental à Saúde e sua dependência das políticas públicas; 2.5 A reserva do possível na garantia de implementação das políticas públicas - 3 . 0 Poder Judiciário como órgão de controle das políticas públicas de saúde - 4 . 0 mínimo existencial como elemento norteador do controle das políticas públicas de saúde: 4.1 Conceito de mínimo existencial; $4.2 \mathrm{~A}$ análise do mínimo existencial para o controle judicial das políticas públicas de saúde; 4.30 acesso à saúde como garantia do mínimo existencial - 5 . Conclusão - 6. Bibliografia.

\section{ApresentaÇão}

O presente artigo faz uma análise da efetividade dos Direitos Sociais, acerca das políticas públicas de saúde. Proporciona um reconhecimento das possibilidades de se exercer controle judicial sobre as políticas sociais e econômicas, além de demonstrar a fundamental importância do exercício desse controle para a efetividade dos direitos fundamentais sociais. Com isso, trataremos das várias decisões que obrigam o atendimento imediato pelo Estado de alguns direitos sociais, notadamente o direito à saúde, que não são concretizados pelo Estado. Isso ocorre porque a falta de recursos públicos impede a efetivação desses direitos. Este trabalho, destarte servirá como uma primeira aproximação para a compreensão das políticas públicas de saúde no Brasil, destacando alguns dos principais eventos, inclusive a judicialização da saúde. Trata ainda da judicialização do Direito à Saúde e do Acesso à Justiça, com o estudo da concretização do mínimo existencial. Além disto, faz uma análise das características, classificação e origem dos direitos sociais, e mostra como o Poder Judiciário lida com as prestações referentes à saúde. 


\section{0 Direito Fundamental à Saúde e a sua efetividade}

\subsection{Breves considerações sobre a classificação dos Direitos Fundamentais}

Os Direitos Fundamentais, ao longo dos tempos, passou por transformações que viabilizaram o acesso cada vez maior a direitos protegidos pelo Estado. Como esses direitos surgiram paulatinamente, houve a necessidade, para facilitar o seu estudo, da classificação desses Direitos Fundamentais de acordo com os momentos em que surgiram.

Dessa forma, a doutrina ${ }^{1}$ classifica os Direitos Fundamentais do homem em gerações ou dimensões. ${ }^{2}$ Estas se subdividem em primeira, segunda, terceira e quarta. ${ }^{3}$ Em linhas gerais, os Direitos da primeira dimensão constituem herança liberal (Direitos de Liberdade). Os Direitos da segunda dimensão são Os Direitos Sociais Econômicos e Culturais, constituindo herança socialista (Direitos de Igualdade). Os de terceira dimensão são Direitos de titularidade coletiva (Direitos de Solidariedade). Os Direitos da quarta compreendem os Diretos à Democracia Direta, ao Pluralismo e à Informação (Direitos da Globalização).

Nesse sentido, Paulo Bonavides ${ }^{4}$ traz a divisão dos Direitos Fundamentais da seguinte forma:

"Os Direitos de primeira geração são os Direitos de Liberdade, os primeiros a constarem do instrumento normativo constitucional, saber, os Direitos Civis e Políticos, que em grande parte correspondem, por um prisma histórico, àquela fase inaugural do constitucionalismo do Ocidente. Os Direitos da segunda geração são os Direitos Sociais, Culturais e Econômicos bem como

1. José Afonso da Silva, Paulo Bonavides, Luiz Alberto David de Araujo e Vidal Serrano, Ingo Wolfgang Sarlet, dentre outros constitucionalistas.

2. A doutrina, de uma forma geral, quando classifica os Direitos Fundamentais utiliza ou o termo geração ou o termo dimensão. O primeiro deixou de ser utilizado pela doutrina contemporânea (Ingo Wolfgang Sarlet, Luiz Alberto David de Araujo, Vidal Serrano, dentre outros) porque pressupõe a sobreposição de uma geração sobre a outra e, por essa razão, o termo dimensão é que está sendo utilizado, pois pressupõe a coexistência entre os Direitos surgidos no decorrer da história da sociedade.

3. O termo quarta dimensão foi desenvolvida por Paulo Bonavides, para ele o Direito à Democracia (direta), o Direito à Informação e o Direito ao Pluralismo comportaria a quarta dimensão "compendiando o futuro da cidadania e o porvir da liberdade de todos os povos" e, somente assim, tornando legítima e possível a tão temerária globalização política.

4. Paulo Bonavides. Curso de direito constitucional, p. 563-564. 
os Coletivos ou de Coletividade. Os Direitos da terceira geração: Direito ao Desenvolvimento, à Paz, ao Meio Ambiente, Propriedade sobre o Patrimônio Comum da Humanidade."

Dessa forma, com expressiva influência da igreja, dos movimentos operários e a expansão do socialismo, a partir do final do século XVIII surgiu a necessidade de assegurar Direitos para a população, banindo, assim, a opressão peculiar do período anterior, principalmente, às revoluções americana e francesa. Dessa forma, o surgimento do Estado Liberal fez com que eclodissem Cartas garantidoras de Direitos Fundamentais com o fito de viabilizar o mínimo acesso das pessoas aos Direitos criados a partir daquele momento.

Infere-se, portanto, que essa transformação no conteúdo garantista das Cartas Constitucionais, que a partir daquele momento surgiram, foi marcada pelo chamado constitucionalismo, movimento que proporcionou a transposição de um Estado cuja característica era não viabilizar acesso a direitos para um Estado garantista.

Nesse momento surgem Direitos decorrentes da ideia de Estado liberal, ou seja, Direitos que não precisam de uma intervenção direta do Estado para que eles possam ser usufruídos pelos atores sociais. Tais Direitos são chamados de negativos ou de primeira dimensão, visto que asseguram a liberdade dos indivíduos a partir da fruição de tais Direitos.

Após o surgimento dos Direitos decorrentes das Revoluções Americana e Francesa, iniciam-se, pelo mundo, transformações que são marcadas pela exploração da atividade laborativa em busca pelo capital e o marco dessas alterações sociais foi a Revolução Industrial no final do século XVIII, cujas consequências sobrevieram mais tarde, quase um século depois, com o reconhecimento dos Direitos dos Trabalhadores.

Tudo isso ajudou à propagação da ideia da conformação da ordem social pelo Estado, a ele incumbindo a tarefa de intervir na economia, de modo a criar condições favoráveis a uma redução do desnível social. Além disso, também se atribuiu ao Estado a responsabilidade para a criação de mecanismos aptos a fazer com que os Direitos Fundamentais, reconhecidos formalmente, pudessem ser alcançados, na prática, por uma gama maior de pessoas.

Diferenciando-se, portanto, dos Direitos de primeira dimensão, essa revolução social fez com que surgissem os Direitos de segunda dimensão (também chamados de Direitos Positivos), decorrentes de um Estado mais interventor e responsável pelos problemas sociais. Verifica-se, destarte, a adoção de um novo perfil estatal, que passa agora a incluir nos textos constitucionais, não apenas normas relativas à organização, poderes e limites do Estado, como também 
destinadas à regulamentação da ordem econômica e social, surgindo uma nova dimensão de Direitos Fundamentais, os Direitos de segunda dimensão.

Para Ingo Wolfgang Sarlet ${ }^{5}$ os Direitos de segunda dimensão:

"Caracterizam-se por outorgar ao indivíduo Direito a prestações sociais por parte do Estado revelando importante mudança no que diz com eficácia das liberdades constitucionais, que agora deixam o plano formal abstrato e passam para o material concreto. Os Direitos de segunda geração abrangem os Direitos à Assistência Social, à Educação, à Saúde, à Segurança, ao Trabalho dentre outros. Além desses Direitos de cunho positivo, também são contempladas as denominadas 'liberdades sociais', de que são exemplos as liberdades de sindicalização e o Direito de Greve."

Por isso na classificação dos Direitos Fundamentais Sociais, verificamos uma prestação que deve ser proporcionada de forma igualitária para todos. Tais prestações, para José Afonso da Silva, ${ }^{6}$ devem proporcionar melhores condições de vida aos mais fracos, direitos que tendem a realizar a igualização de situações sociais desiguais.

Nesse liame, José Afonso da Silva ${ }^{7}$ observa que os Direitos Sociais poderiam ser classificados como Direitos Sociais do homem como produtor e como consumidor. Na primeira classificação, Direitos Sociais do homem produtor, teria a liberdade de instituição sindical, o Direito de Greve, o Direito de o trabalhador determinar as condições de seu trabalho, o Direito de cooperar na gestão da empresa e o Direito de obter emprego (arts. $7 .^{\circ}$ a 11 da CF/1988). Na segunda classificação, Direitos Sociais do homem consumidor, teria o Direito à Saúde, à Segurança Social, ao Desenvolvimento Intelectual, o Igual Acesso das Crianças e Adultos à Instrução, à Formação Profissional e à Cultura e Garantia ao Desenvolvimento da Família, que estariam no título da Ordem Social.

Desde o tempo das sociedades modernas, as Constituições começaram a contemplar o aparecimento de novos Direitos que são os chamados de terceira dimensão. Foram também de grande prestígio os Direitos de quarta dimensão, que se referem à globalização política, Direito à Informação, Direito a Democracia e ao Pluralismo.

5. Ingo Wolfgang Sarlet. A eficácia de direitos fundamentais, p. 48.

6. José Afonso da Silva. Curso de direito constitucional positivo, p. 52.

7. Idem, p. 565. 


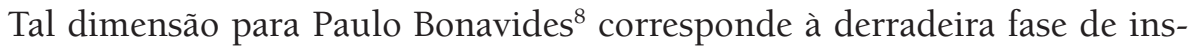
titucionalização do Estado Social. Nessa dimensão encontramos os Direitos à Democracia, à Informação e o ao Pluralismo, deles dependem a concretização da sociedade aberta do futuro, em sua dimensão de máxima universalidade, para qual parece o mundo inclinar-se no plano de todas as relações de convivência.

A classificação dos Direitos Fundamentais teve por objetivo, portanto, facilitar o estudo de tais Direitos, bem como de proporcionar uma visão ampla de desenvolvimento dos Direitos Fundamentais no Brasil.

\subsection{O Direito à Saúde como Direito Fundamental Social}

O Direito à Saúde é Direito Fundamental Social previsto inicialmente no art. $6 .^{\circ}$ e, posteriormente, no art. 196 e ss., da CF/1988. Trata-se de Direito de todos e dever do Estado, onde este deve implementar meios para viabilizar o acesso às políticas sociais de saúde descritas em lei (Lei 8.080/1990), com a finalidade de assegurar o acesso universal e igualitário às medidas preventivas, bem como repressivas.

A saúde, como Direito Fundamental Social, tem por objetivo garantir aos indivíduos condições materiais imprescindíveis para o pleno gozo dos demais Direitos. Para Paulo Bonavides, ${ }^{9}$ os Direitos Sociais fizeram nascer a consciência de que tão importante quanto salvaguardar o indivíduo, era proteger a instituição brasileira. Para ele a saúde encontra-se entre os bens intangíveis mais preciosos do ser humano, digna de receber a tutela protetiva estatal, porque se consubstancia em característica indissociável do Direito à Vida.

Nesse sentido, posicionou-se o STF: ${ }^{10}$

"Ementa: Pacientes com esquizofrenia paranoide e doença maníaco-depressiva crônica, com episódios de tentativa de suicídio. Pessoas destituídas de recursos financeiros. Direito à Vida e à Saúde. Necessidade imperiosa de se preservar, por razões de caráter ético jurídico, a integridade desse Direito essencial. Fornecimento gratuito de medicamentos indispensáveis em favor de pessoas carentes. Dever constitucional do Estado (arts. 5. ${ }^{\circ}$, caput, e 196 da CF/1988). Precedentes (STF). Abuso do Direito de Recorrer. Imposição de

8. Idem, ibidem.

9. Paulo Bonavides. Curso de direito constitucional, p. 565.

10. STF, AgRg em RE, 2. ${ }^{a}$ T., j. 12.12.2006, rel. Min. Celso de Mello, DJ 02.02.2007, p. 140, Ementário, vol. 02262-08, p. 1524. 
multa. Recurso agravado improvido. O direito à saúde representa consequência constitucional indissociável do direito à vida. (...) O Poder Público, qualquer que seja a esfera institucional de sua atuação no plano da organização federativa brasileira, não pode mostrar-se indiferente ao problema da saúde da população, sob pena de incidir, ainda que por censurável omissão, em grave comportamento inconstitucional" (grifamos).

Entende-se que a saúde não é meramente um estado biológico, é uma questão de cidadania e de justiça social. Por isso, a Declaração Universal dos Direitos Humanos (DUDH), aprovada pela Res. 217 da Assembleia Geral da ONU, traz no seu art. XXV, que toda pessoa tem Direito a um padrão de vida capaz de assegurar a si e a sua família saúde e bem estar, assim como cuidados médicos e Direito à Segurança em caso de doença, ou seja, consagra a saúde como um verdadeiro estado de bem-estar.

O Direito à Saúde é, portanto, reconhecido na legislação nacional e internacional, como um Direito Fundamental Social que deve ser garantido pelos Estados aos seus cidadãos, por meio de políticas e ações públicas que permitam o acesso de todos aos meios adequados para o seu bem-estar. Para isso, os países signatários das declarações internacionais "devem adotar um comportamento progressivo de modo a assegurar um mínimo necessário para garantir a saúde física e mental para todas as pessoas". ${ }^{11}$

A trajetória do reconhecimento do Direito à Saúde como relativo à dignidade humana ${ }^{12}$ e sua derivação nas leis, políticas públicas e jurisprudências, mostram a preocupação sobre o conceito de saúde, e como atingir o estado de bem-estar, e quais são direitos e deveres dos cidadãos e dos Estados.

A Lei 8.080/1990 dispõe sobre as condições para a promoção, proteção e recuperação da saúde, a organização e o funcionamento dos serviços correspondentes e dá outras providências. Tal legislação prevê que todos os seres humanos têm Direito à prestação dos serviços de saúde básica e de especialidades, devendo estes serem fornecidos pelo Estado.

Dessa forma, o Direito à Saúde deve ser analisado de forma ampla, englobando a possibilidade de garantir, por parte do Estado, um mínimo de dignida-

11. Luciana Jordão da Motta Armiliato de Carvalho, Sobre a política de dispensação de medicamentos no Brasil: mínimo necessário para a efetivação do direito à saúde. Revista de Direito Social, n. 29, ano 8, p. 119.

12. Nesse sentido, Carlos Weis. Direitos humanos contemporâneos, p. 118, assevera que "só há vida verdadeiramente digna se todos os Direitos previstos no Direito Internacional dos Direitos Humanos estiverem sendo respeitados, sejam civis e políticos, sejam econômicos, sociais e culturais". 
de e bem-estar ao hospitalizado, não restringindo somente aos casos de risco de morte ou de grave lesão sofrida pelo paciente. Com isso, inserem-se no Direito Fundamental à Saúde os medicamentos ou tratamentos médicos que não são fornecidos pela administração do Sistema Único de Saúde - SUS além das políticas de vigilância sanitária, em observância de que a norma constitucional do art. 196 tem natureza elástica e caráter imperativo sobre as normas regulamentares administrativas baixadas pelo Poder Executivo. Para tanto, o Estado deve contemplar as atividades de saúde de todos os níveis.

\subsection{A efetividade do Direito Fundamental à Saúde, políticas públicas e seus limites}

O Direito à Saúde é Direito Fundamental Social e, dada à sua importância, deve ser garantido de forma incondicionada pelo Estado, em todas as suas dimensões, afinal, ao assegurar tal Direito à sociedade, o Estado está cumprindo seu papel, tutelando o bem maior previsto no texto constitucional que é o bem da vida proporcionando dignidade ao ser humano.

Logo, restringir o Direito a Saúde não é pertinente no sistema jurídico brasileiro de nenhuma forma, já que possui aplicabilidade plena e imediata, e não possibilita qualquer mitigação a este direito, sob pena de afrontar diretamente o texto constitucional.

O Estado deve promover o acesso à saúde de forma imediata por se tratar de direito fundamental do homem, como afirma Germano Schwartz:

"Tornando a norma do art. 196 da CF/1988 autoaplicável e de eficácia imediata. Que as políticas públicas de saúde são o meio primeiro de efetivação deste Direito (conforme a locução do texto constitucional expressa em seu art. 196), e que a atuação do Poder Judiciário ocorre em um momento posterior, onde se constata a não ação ou inércia estatal na proteção do direito à saúde." ${ }^{13}$

Dessa forma, no Direito à Saúde deve-se destacar a necessidade da tutela jurisdicional com a finalidade de tornar eficaz o seu acesso quando o Estado não cumpre a disposição prescrita na Constituição de 1988.

Por essa razão a necessidade de controle, por parte da sociedade, da atuação do Estado na implementação do Direito à Saúde a partir da criação de políticas públicas que façam concretizar o seu acesso à saúde, priorizando a prevenção, mas sem deixar de lado, é claro, as medidas curativas que atuam nas doenças já instaladas, tem primacial importância no âmbito dos Direitos Sociais porque

13. Germano Schwartz, Direito à saúde: efetivação em uma perspectiva sistêmica, p. 57. 
estes dependem de uma atuação direta por parte do Poder Público já que se incluem na esfera dos Direitos Positivos.

A efetividade do Direito à Saúde representa, dessa forma, um desafio para a sociedade e para o Estado que está sendo superado à medida que o Poder Público assume um comportamento progressivo nas medidas de proteção à saúde, garantindo, com isso, maior desenvolvimento nacional (art. 3. ${ }^{\circ}$, II, da CF/1988).

Para tanto a Constituição Federal, no art. $6^{\circ}{ }^{\circ}$ prevê os Direitos Sociais ${ }^{14}$ que, para serem implementados, necessitam de ações positivas do Estado, já que se apresentam em constante crescimento de demanda. Na área da saúde, a necessidade de proteção é bem visível, devido à existência intensa de procura de fornecimento gratuito de medicamentos, tratamentos e exames.

As políticas públicas, destarte, são programas de ação governamental visando a coordenar os meios à disposição do Estado e os planos privados, para a realização de metas socialmente relevantes e politicamente determinadas. Em se tratando do Direito à Saúde, as suas políticas públicas, nos últimos tempos, têm sido de grande importância para a população de todo o país, mesmo sabendo que a sua implementação não tenha sido aplicada de forma justa e satisfatória.

Historicamente, as políticas públicas e especialmente no Brasil, caracterizam-se de forma dependente dos interesses econômicos e políticos, sendo implementadas através de práticas assistencialistas e clientelistas, refletindo relações que não incorporam o efetivo reconhecimento dos Direitos Sociais.

Observa-se, portanto, a existência de um modelo de relações que fragmenta e desorganiza a classe subalterna ao apresentar como favor os Direitos do cidadão. Percebe-se ainda o crescimento da dependência de segmentos cada vez maiores da população, no que se refere à intervenção estatal, por não dispor de meios para satisfação de suas necessidades cotidianas.

No que concerne às Políticas de Saúde no Brasil, mesmo após a Constituição de 1988, que instituiu o Sistema Único de Saúde - SUS, o perfil da organização de programas e serviços de saúde ainda se apresenta caracterizado pela centralização, pelo governo federal, de diretrizes e prioridades para o setor de saúde, destinadas às esferas estaduais e municipais, não cumprindo efetivamente com a prescrição constitucional da descentralização prevista no art. 198 da Lei das leis.

14. O art. $6 .^{\circ}$ da CF/1988 diz que: "São Direitos Sociais a educação, a saúde, o trabalho, a moradia, o lazer, a segurança, a previdência social, a proteção à maternidade e à infância, a assistência aos desamparados, na forma desta Constituição". 
Por outro lado, a acentuada privatização define o investimento no setor de saúde com recursos do orçamento da União produzidos pelo setor privado, visualizadas na realidade do país, principalmente através do fortalecimento dos planos de saúde.

Nesse sentido, constata-se que o conjunto de ações destinadas aos Estados e municípios distancia-se das reais condições de saúde vivenciadas pela população brasileira. Como consequência, a população usuária recebe uma prestação de serviços.

Para que seja possível adequar a participação do Estado por meio das políticas públicas, torna-se inevitável observar as condições objetivas e os elementos que afetam a sua realização. O principal elemento que dificulta a eficácia das políticas públicas é o elemento financeiro. Dessa forma, não há como considerar, implementar e controlar as políticas públicas desconsiderando os recursos financeiros.

Ingo Wolfgang Sarlet ${ }^{15}$ afirma que o Estado dispõe apenas de limitada capacidade de dispor sobre o objeto das prestações reconhecidas pelas normas definidoras dos Direitos Fundamentais Sociais, de tal sorte que a questão da limitação dos recursos constitui certo limite fático à efetivação desses Direitos.

A inegável limitação de recursos para atender a todas às necessidades dos indivíduos não se deve inviabilizar a proteção de um conjunto mínimo de condições para que eles possam viver de forma digna. Mesmo com o elemento limitador das políticas públicas - recursos financeiros - não se pode aceitar que seja o único argumento para justificar o fato de não atenderem às demandas decorrentes da garantia dos Direitos Fundamentais Sociais, principalmente o Direito à Saúde.

É necessário, portanto, encontrar soluções para que tenha um equilíbrio entre a limitação dos recursos públicos e o dever do Estado de concretizar os Direitos Sociais. É importante a racionalização, a padronização e estabelecimento de critérios para que ocorra o atendimento, por parte do Estado, das demandas sociais.

\subsection{O Direito Fundamental à Saúde e sua dependência das politicas públicas}

Os Direitos Sociais materializam-se com a entrega de determinadas utilidades concretas, como é o caso da saúde pública. Não basta que o Estado inclua, em âmbito constitucional, uma vasta lista de Direitos Sociais em prol

15. Ingo Wolfgang Sarlet. Op. cit., p. 227. 
do cidadão. São deveres estatais planejar suas ações e realizar esses Direitos no plano concreto, cumprindo os mandamentos constitucionais, especialmente os relacionados à dignidade da pessoa humana. Dessa forma, esse dever estatal de planejamento e realização das prestações positivas garantidoras dos Direitos Sociais se efetiva por meio das políticas sociais.

Ingo Wolfgang Sarlet, ${ }^{16}$ além de salientar a dificuldade para definir o conteúdo prestacional do direito em tela, ainda se refere à questão prática, haja vista que a realização destes Direitos depende da disponibilização de meios e, também, da progressiva implementação e execução de políticas públicas na esfera socioeconômica.

Desse modo, resta a certeza que o gozo do Direito Social à Saúde dependerá de ações governamentais, cuja realização desses Direitos irá consumir consideráveis recursos públicos. Com isso, pode-se afirmar que a constitucionalização do Direito à Saúde na atual Carta Política possui duas características principais: o seu reconhecimento como Direito Fundamental Social e a definição dos princípios que regem a política pública de saúde.

Dessa forma, a implementação dos Direitos à Saúde dependerá diretamente da adoção de políticas públicas pelos entes estatais. A partir dessa premissa, não se pode negar a natureza programática do Direito à Saúde, nem a possibilidade de escolha governamental entre as várias condutas possíveis e aptas para promover o acesso universal aos serviços de saúde.

Diante da inescapável dependência de uma contribuição financeira e orçamentária para a implementação das políticas públicas que irão garantir os Direitos Sociais, Ingo Wolfgang Sarlet, é eficaz ao afirmar que o Estado possui apenas limitada capacidade de dispor sobre o objeto das prestações sociais. De maneira clara e incisiva, referido autor ${ }^{17}$ diz que:

"O que a Constituição assegura é que todos tenham, em princípio, as mesmas condições de acessar o sistema público de saúde, mas não que qualquer pessoa, em qualquer circunstância, tenha um Direito subjetivo definitivo a qualquer prestação oferecida pelo Estado ou mesmo a qualquer prestação que envolva a proteção à saúde."

Assim, a Administração Pública possui a prerrogativa constitucional de escolher, pelas medidas que melhor atendam às necessidades da população, como um todo, os meios que reflitam com eficiência os reais interesses da

16. Idem, p. 298.

17. Idem, p. 376. 
sociedade. Dessa forma, cabe ao Poder Executivo, constituir, com base nas diretrizes constitucionais, os critérios para a adoção das políticas públicas de saúde, com vistas a garantir todas as medidas de proteção à sociedade no que tange ao acesso à saúde.

\subsection{A reserva do possivel na garantia de implementação das políticas públicas}

As políticas públicas atuam de forma complementar à legislação, cuja característica é a generalidade e abstração, como meio de rematá-la e de concretizar seus princípios e regras, perseguindo objetivos certos e determinados. O Estado brasileiro possui algumas políticas públicas voltadas à realização de seus preceitos legislativos, mas estas devem ser sempre destinadas à consecução do bem comum e da dignidade da pessoa humana. "A essência de qualquer política pública é distinguir e diferenciar, realizando a distribuição dos recursos disponíveis na sociedade." 18

O Estado, ao executar as políticas públicas necessárias à concretização dos Direitos Sociais, tem que disponibilizar recursos públicos suficientes para a consecução de seus programas de proteção social. Ao se interpretarem os Direitos Constitucionais, é preciso ter conhecimento da realidade dos elementos jurídicos, sendo eles as condições financeiras e materiais de realização da norma.

Dessa forma, a escassez de recursos financeiros demonstra que os Direitos Fundamentais possuem uma dimensão econômica comum, atrelada aos custos requeridos para que sejam concretizados. A questão da existência ou não de recursos disponíveis para atender às prestações positivas a cargo do Estado tem sido orientada no Brasil pela teoria da reserva do possível.

A reserva do possível traduzida como insuficiência de recursos, também denominada reserva do financeiramente possível, tem aptidão de afastar a intervenção do Poder Judiciário na efetivação de Direitos Fundamentais apenas na hipótese de comprovação de ausência de recursos orçamentários suficientes para tanto. Para Fernando Mânica19 "Tal viés da teoria da reserva do possível é importante e deve ser entendido com o objetivo de vincular o Direito à Economia, no sentido de que as necessidades, mesmo aquelas relacionadas aos Direitos Sociais, são ilimitadas e os recursos são escassos".

18. Andreas J. Krell. Direitos sociais e controle judicial no Brasil e na Alemanha: os descaminhos de um direito constitucional comparado, p. 101.

19. Fernando Borges Mânica. Racionalidade jurídica e racionalidade econômica na Constituição de 1988, p. 12. 
A teoria da reserva do possível tem sido interpretada como limitação à efetivação de Direitos Fundamentais Sociais em face da incapacidade jurídica do Estado em dispor de recursos para a efetivação do Direito. Essa teoria não pode servir como barreira para a não realização dos Direitos e prestações sociais. Ela não pode ser usada como desculpa para omissão Estatal no campo da efetivação dos Direitos Fundamentais Sociais. Infere-se, com isso, que não se pode negar a prestação do Direito à Saúde/Vida sob o argumento da indisponibilidade de recursos.

Não havendo recursos financeiros disponíveis para suprir as necessidades sociais, cabe ao administrador público priorizar o Direito à Saúde em detrimentos de outros Direitos que não possuem o mesmo grau de essencialidade, implementando políticas públicas possíveis de serem concretizadas diante da previsão orçamentária.

Dessa forma, as escolhas realizadas pelo Estado devem ser pautadas pela Constituição Federal, documento que estabelece os objetivos fundamentais que deverão ser satisfeitos pela autoridade estatal. Vê-se, a partir disso, que a vinculação dos gastos públicos aos objetivos constitucionais é lógica.

Em decorrência da importância deste Direito e visando não deixar decisões importantes como a que envolve a tutela do Direito à Saúde sob o poder discricionário do legislador, foi que o Estado criou a possibilidade do Poder Judiciário interferir sempre que o Direito Fundamental a Saúde estiver na iminência de sofrer grave lesão, como nos casos em que a sobrevivência da pessoa depende de cirurgia, e esta, por sua vez, não foi realizada, pelo Poder Público, sob a alegação genérica de falta de recursos financeiros. É válido ressaltar que o Poder Judiciário só pode intervir apenas em casos extraordinários, sendo em regra, dever do Estado à concretização do Direito à Saúde. ${ }^{20}$

20. Segundo Ingo Wolfgang Sarlet, A eficácia dos direitos fundamentais, p. 280: "justamente pelo fato de os Direitos Prestacionais terem por objeto prestações do Estado diretamente vinculadas à destinação, distribuição (e redistribuição), bem como à criação de bens materiais, aponta-se, com propriedade, para sua dimensão economicamente relevante". Assim, os Direitos Sociais, assim como todos os Direitos Fundamentais, custam para o Estado e sua concretização "pelos órgãos do Poder Judiciário (...) nunca constitui um elemento impeditivo da efetivação pela via jurisdicional" (idem, p. 281). E, "no que diz com os Direitos Sociais à Prestações, seu 'custo' assume especial relevância no âmbito de sua eficácia e efetivação, significando, pelo menos para significativa parcela da doutrina, que a efetiva realização das prestações reclamadas não é possível sem que se despenda algum recurso, dependendo, em última análise, da conjuntura econômica, já que aqui está em causa a possibilidade de os órgãos jurisdicionais imporem ao poder público a satisfação das prestações reclamadas" (idem, ibidem). 
Segundo a teoria da reserva do possível, decisões que envolvem Direitos Fundamentais, como o Direito à Saúde, devem ser sempre objeto de ponderação pelo Estado, de acordo com o princípio da proporcionalidade. E, após inúmeros questionamentos acerca da aplicabilidade da teoria da reserva do possível à realidade brasileira, os tribunais têm se posicionado no sentido de que cabe ao administrador escolher a saúde como uma prioridade, alocando recursos para a concretização desse Direito não sendo mais aceita a justificativa genérica de escassez de recursos para o descumprimento desse Direito Fundamental.

\section{O Poder JUdicIÁRIO COMO ÓRGÃO dE CONTROLE dAS POLITICAS PÚBLICAS DE SAÚDE}

O acesso à Justiça não se limita apenas ao ingresso formal do paciente com um processo judicial e a concessão, pura e simplesmente, de um pedido do cidadão, mas significa a garantia de uma solução justa, no sentido de produzir uma adequada prestação jurisdicional, cumprindo, principalmente, com o mister constitucional. Espera-se do paciente a resolução do conflito, garantindo-se materialmente o resguardo do Direito à Saúde dos cidadãos, com o fornecimento do medicamento necessário, seguro e eficaz para seu tratamento de saúde.

Portanto, o acesso à Justiça é considerado de forma mais ampla, como o acesso aos benefícios jurídicos em geral no nível legislativo e administrativo, além de se estabelecer um consenso entre as partes envolvidas e afetadas pelas decisões judiciais nesse âmbito, porque implica decidir sobre o que é justo e do pluralismo moral existente nas sociedades democráticas.

Pode-se afirmar que o controle judicial das políticas sociais de saúde é recomendável, necessário e indispensável. Barroso, ${ }^{21}$ preocupado com os graves sintomas que atual sistema brasileiro de controle da saúde pública começa a apresentar, entende que a falta de critérios seria um dos motivos para essa situação preocupante.

Assim, para que sejam fixadas balizas seguras e objetivas para solucionar esses casos de colisão de Direitos Fundamentais, é necessário analisar o princípio da proporcionalidade, que é o primeiro limite à concretização judicial do Direito à Saúde.

O Poder Judiciário assume papel importante e decisivo no acesso ao Direito à Saúde na medida em que a inércia do Estado inviabiliza a proteção à saúde.

21. Luís Roberto Barroso. Apontamentos sobre as agências reguladoras, p. 222. 
Dessa forma, como se trata de Direito Fundamental, constitucionalmente previsto, de aplicabilidade imediata em razão da sua essencialidade para a garantia do Direito à Vida e a Manutenção da Dignidade da Pessoa Humana, o Estado não deveria se eximir da responsabilidade em proporcionar saúde aos que dela necessitam por intermédio do SUS - Sistema Único de Saúde. Em se verificando uma hipótese da omissão ou inércia por parte do Poder Público, o indivíduo que se viu violado no acesso ao Direito à Saúde, deve recorrer ao Poder Judiciário para que este, baseado nas premissas constitucionais, viabilize o acesso à saúde e, por consequência, proteja a vida dessa pessoa que se viu aviltrada no seu Direito à Saúde.

O Poder Judiciário tem a função de aplicar o Direito de acordo com a complexidade de cada caso, dando ao juiz certa liberdade ao julgar, em escolher as interpretações cabíveis. Não tem mais a simples função de verificar a ocorrência da hipótese prevista em lei e aplicar os efeitos jurídicos, como antigamente era feito.

Não basta decidir simplesmente, é necessário que o Poder Judiciário decida de forma legítima, construtiva, proporcional, harmônica com a realidade social, comprometida com os valores existentes na Constituição. Dessa forma, as decisões judiciais devem ser realizadas com a consciência da sua repercussão social na vida comunitária.

Embora os Direitos Sociais tenham força normativa (porque tem conteúdo constitucional), e ocupem espaço de destaque na Constituição Federal, não são autoaplicáveis. Isso decorre do tipo de classificação que enquadra as normas de direitos sociais como de eficácia limitada, ou seja, dependem de regulamentação pelo legislador infraconstitucional. E mesmo com a edição da lei infraconstitucional, esta no plano prático, ainda não é suficiente para concretizar tais Direitos. Por essa razão é que o Poder Judiciário é acionado para que os Direitos Prestacionais se tornem efetivamente aplicados no plano prático.

Infere-se, com isso que um Judiciário criativo, ousado e, ao mesmo tempo, humilde ainda não é suficiente para possibilitar uma boa concretização judicial de Direitos Fundamentais. É necessária uma boa estrutura que permita o desenvolvimento da litigiosidade dos Direitos Fundamentais Sociais, estrutura esta que passa desde a educação e conscientização em Direitos Fundamentais (cidadania popular em Direitos Fundamentais) até a efetiva concretização, no estágio final do processo, das ordens proferidas pelos juízes, estruturando devidamente o Judiciário, o processo e a própria máquina estatal ${ }^{22}$ como um todo.

22. EC 45/2004. 
Verifica-se, destarte, que o atual Poder Judiciário, no exercício do controle das políticas sociais, é bem presente, principalmente na área do Direito Fundamental à Saúde. E ao fazer uma análise jurisprudencial dos julgados no setor da saúde, percebe-se que é grande a presença das prestações ligadas a esse Direito Social.

O fenômeno da judicialização da saúde expressa reivindicações e modos de atuação legítimos de cidadãos e instituições, para a garantia e promoção dos Direitos de Cidadania amplamente afirmados nas leis internacionais e nacionais. O fenômeno envolve aspectos políticos, sociais, éticos e sanitários, que vão muito além de seu componente jurídico e de gestão de serviços públicos.

Ao tutelar o Direito à Saúde, deve o Judiciário atentar para que, ao proteger o referido bem jurídico, não passe a substituir totalmente a competência do poder que possua competência originária para isso. Como assevera o Des. Genaro Baroni Borges, integrante da 21. ${ }^{a}$ Câmara Cível do TJRS: "O sistema de saúde se tornou 'judicializado' porque chegam ao TJ questões que não deveriam chegar". ${ }^{23}$ Como consequência verifica-se que "o Judiciário, tanto quanto o paciente, é vítima da situação carente do Estado e se vê incumbido de administrar a escassez de recursos públicos, quando essa não é a sua função". ${ }^{24}$

Cabe ressaltar que, ao exercer função imprópria sem, no entanto, exigir como condição da ação que, preliminarmente, os pacientes intentem o acesso aos seus Direitos mediante as vias administrativas, o Judiciário passaria a exercer não subsidiariamente a função de fiscalizador das decisões dos outros poderes, passando a exercê-las de forma plena. ${ }^{25}$

Germano Schwartz observa que:

"A atuação judicial far-se-á em um momento posterior ao da constatação de que as ações positivas estatais não garantiram o Direito à Saúde. É, portanto, uma atuação secundária (mas não suplementar) em relação ao dever dos Poderes Públicos - especialmente o Executivo, pois inexistiria necessidade de uma decisão derivada do sistema jurídico caso tais Poderes cumprissem o seu papel." ${ }^{26}$

23. Douglas Ceconello. Sistema de saúde se tornou judicializado, p. 1.

24. Idem, ibidem.

25. Como a via administrativa é a primeira que se deve recorrer para ter acesso aos serviços de saúde, o administrado, paciente do SUS (Sistema Único de Saúde), não pode pleitear diretamente ao Judiciário algo que, para sua concessão, bastaria uma simples decisão da Administração Pública.

26. Germano Schwartz. Direito à saúde: efetivação em uma perspectiva, p. 162. 
Diante disso, as políticas públicas de saúde devem seguir a diretriz de reduzir as desigualdades econômicas e sociais. Contudo, quando o Judiciário assume o papel de protagonista na implementação dessas políticas, privilegia aqueles que possuem acesso qualificado à Justiça, seja por conhecerem seus Direitos, seja por poderem arcar com os custos do processo judicial. Por isso, a possibilidade de o Judiciário determinar a entrega gratuita de medicamentos mais serviria à classe média que aos pobres. Inclusive, a exclusão destes se aprofundaria pela circunstância de o Governo transferir os recursos que lhes dispensaria em programas institucionalizados, para o cumprimento de decisões judiciais, proferidas, em sua grande maioria, em benefício da classe média.

\section{O MínIMO EXISTENCIAL COMO ELEMENTO NORTEADOR DO CONTROLE DAS POLITICAS PÚBLICAS DE SAÚDE}

\subsection{Conceito de mínimo existencial}

Um dos mais fortes argumentos em defesa da exigibilidade dos Direitos Fundamentais e sua aplicabilidade imediata é a sua relação com o princípio basilar do Direito, Dignidade da Pessoa Humana. Tal princípio, "apresenta-se como núcleo intangível dos Direitos Fundamentais". ${ }^{27}$ É por meio desse argumento que se busca a efetivação do mínimo existencial, ou seja, é dever do Poder Público para assegurar a preservação da dignidade da pessoa humana, o fornecimento do mínimo essencial de sobrevivência para o indivíduo.

O mínimo existencial é Direito Fundamental, vinculado à Constituição, sendo irrelevante a existência de lei para sua obtenção. É princípio que está ligado à ideia de liberdade, enquanto que os direitos econômicos e sociais estão vinculados à justiça. Nesse sentido, as normas que conferem direitos econômicos e sociais classificam-se como normas programáticas.

Para Ricardo Lobo Torres: ${ }^{28}$

"Sem o mínimo necessário a existência cessa a possibilidade de sobrevivência do homem e desaparecem as condições iniciais da liberdade. A dignidade e as condições materiais da existência não podem retroceder aquém de um mí-

27. Nagibe de Melo Jorge Neto. O controle jurisdicional das politicas públicas: concretizando a democracia e os direitos sociais, p. 153.

28. Ricardo Lobo Torres. O direito ao mínimo existencial, p. 35. 
nimo do qual nem os prisioneiros, os doentes mentais e os indigentes podem ser privados."

O legislador através do caso em espécie poderá reconhecer o quanto e como será prestada a política pública para assegurar sua efetivação e, na omissão ou ineficaz atuação dessa atividade por parte do legislador, é que o Poder Judiciário intrometer-se-á desde que acionados. A questão do mínimo existencial não é só de cunho social, ou seja, sua prestação não se dará apenas com a elaboração de programas assistenciais ou de saúde, é necessária a alocação de verbas, melhor dizendo, a arrecadação cada vez maior de recursos para que seja assegurada ao cidadão uma qualidade de vida superior a que realmente ele goza.

Dessa forma, a efetivação do mínimo existencial, ou seja, a prestação positiva por parte do Poder Público, de políticas públicas que garantam o essencial de Direitos Sociais ao cidadão, depende além da atuação do legislador na elaboração de programas assistenciais, como também, na captação de recursos que tenham como fim a exaltação das normas programáticas elencadas na Constituição.

\subsection{A análise do mínimo existencial para o controle judicial das politicas públicas de saúde}

No que diz respeito ao Direito Social à Saúde, a aplicação do que corresponde ao mínimo existencial será através do caso concreto, deve haver um esclarecimento entre o que será excesso à prestação, posto que, o Direito à Vida Humana estaria em evidência, como também, a escassez de recursos públicos, bem como, os demais indivíduos que não necessitam especificamente de determinado tratamento.

As políticas sociais têm de garantir, pelo menos, a concretização do mínimo existencial e, à medida que esse mínimo for se efetivando, deve-se reavaliar o alcance das políticas para ir se aproximando, gradativamente, do ideal idealizado pela Constituição. Se a atuação do Judiciário, no controle das políticas sociais, for balizada por esse mínimo existencial, não haverá tantos problemas institucionais na seara da saúde pública.

Pode-se idealizar as consequências práticas de uma atuação abusiva e excessiva do Poder Judiciário no âmbito da saúde. As concessões individualizadas, certamente, não representam, nem irão representar a solução adequada para os graves problemas do sistema público de saúde.

O Direito à Saúde, que, além de ser um Direito Fundamental Social Prestacional do Poder Público, é também um Direito de Defesa, de proteção contra atos do Estado ou de particulares. Dessa forma, ao fazer referência à Constitui- 
ção brasileira, a doutrina atual se projeta no sentido de dar plena aplicabilidade às normas constitucionais que regem os Direitos Fundamentais Sociais Prestacionais, em especial, os Direitos Sociais. Ela não esvazia o mínimo existencial e mantém a sua condição de Direito e garantia, independentemente de sua previsão constitucional expressa, não dispensando a análise de cada caso concreto.

Além disso, é pertinente ressaltar que as decisões do Poder Público para a construção de suas metas de ação não são invioláveis, impenetráveis pelo Poder Judiciário, construindo-se a noção de que no âmbito do Estado Democrático de Direito é possível controlar as políticas públicas.

\subsection{O acesso à saúde como garantia do mínimo existencial}

Não há como questionar que os Direitos geram um custo para Estado. Mas isto não significa que este pode se escusar do dever de possibilitar ao cidadão ter acesso a saúde. Portanto, a simples justificativa de que não há falta de recursos, sem uma fundamentação não é mais aceitável, pois se assim o fosse, bastaria o administrador afirmar que não há recursos para ficar livre do seu dever constitucional.

Como afirma Fabiana Rodrigues Barletta:29 “(..) se há escassez de recursos financeiros, o que estiver disponível será obrigatoriamente aproveitado na persecução dos Direitos considerados fundamentais pela normativa constitucional até que esses sejam alcançados".

Por ser um Direito Fundamental, o acesso a saúde é Direito de todos os cidadãos e dever do Estado, portanto, se há escassez de recursos, este Direito deve ser priorizado em detrimento de outros Direitos, que não têm o mesmo grau de fundamentalidade que fora concedido pela Constituição à saúde.

Além disso, o Direito á Saúde requer medidas urgentes não pode se prolongar no tempo, pois, a saúde está intimamente ligada ao bem maior que é a vida, portanto deve ser tal Direito concretizado o mais rápido possível, pois o que está em jogo é a própria vida do ser humano.

Em decorrência do exposto os tribunais brasileiros têm concedido de imediato a tutela jurisdicional, quando a lide envolve o acesso à saúde.

"Constitucional. Marcação de exame médico. Paciente idoso. Decisão agravada que deferiu antecipação de tutela para marcação de exames médicos necessários ao réu, ora agravado, no prazo de 48 horas sob pena, de multa fixada

29. Fabiana Rodrigues Barletta. O direito à saúde da pessoa idosa, p. 138. 
em R\$ 300,00. Obrigação solidária dos Entes Federativos. Matéria pacificada pela Súmula n. 65 deste egrégio TJ. Deriva-se dos Direitos Mandamentais dos arts. 6. ${ }^{\circ}$ e 196 da CF/1988 e da Lei 8.080/1990, a responsabilidade solidária da União, Estados, e Municípios, garantindo o fundamental Direito à Saúde e consequentemente antecipação da respectiva tutela." 30

O que se deseja com medidas como a concessão de tutela é garantir ao cidadão a concretização do Direito à Saúde, como forma de garantir ao cidadão o mínimo essencial á uma existência humanamente digna.

E esta garantia ao mínimo essencial nada mais é que a garantia do mínimo existencial, ou como prefere denominar Ingo Wolfgang Sarlet, dos Direitos Fundamentais, que são os elementos essenciais para o exercício da dignidade humana, o que não confunde com mínimo vital, este é restrito ao mínimo necessário a sobrevivência.

Como afirma Ricardo Lobo Torres, "o mínimo existencial, tem força de Direito, pois está implícito no princípio da dignidade da pessoa e na ideia de um Estado Social de Direito". O Direito ao mínimo existencial é concretizado pelo Poder Público, quando este, por exemplo, distribui gratuitamente remédios na rede pública de saúde. Possibilitando assim o acesso do cidadão á saúde, direito fundamental e exigível.

Segundo Gustavo Amaral:

"O mínimo existencial tem sua extensão aprofundada e, inclusive, maximizada, na medida da essencialidade de bem que o Estado irá prestar, porque sua substância do Princípio da Dignidade Humana, razão pelo qual o mínimo existencial em matéria de saúde, e, particularmente, em questões que envolvem a saúde da pessoa idosa, Direito de ordem prioritária e componente do teor do Princípio da Dignidade Humana, é, dessa forma, alargado." 31

É válido ainda ressaltar que no que se refere à saúde, este não é só um Direito de acesso como também de respeito à integridade física e psíquica do ser humano, como forma de preservar o bem maior que é a vida.

\section{ConCLUSÃ̃}

O Direito à Saúde é um Direito Fundamental Social, que deve ser garantido pelo Estado, através das políticas e ações públicas, para salvaguardar os indiví-

30. Decisão retirada da obra de Fabiana Rodrigues Barletta, op. cit., p. 143 (TJRJ, AgIn 2006.002.12199, Agravante: Município do Rio de Janeiro, Agravado: Adilson Mattoso de Gouvêa, rel. Des. Antonio Ibrahim, julgada em 2007).

31. Gustavo Amaral. Direito, escassez e escolha: em busca de critérios jurídicos para lidar com a escassez de recursos e as decisões trágicas, p. 215. 
duos, proporcionando um mínimo necessário para a efetivação desse Direito. Cumpre salientar que não se pode pensar em vida digna sem saúde, pois a ela é o principal requisito para uma vida minimamente satisfatória.

Apesar da grande importância do Direito à saúde, não é de forma plena e satisfatória que eles são executados pelo poder estatal. Não há na prática ações governamentais para garantir o gozo deste Direito Social, e por isso é necessário que o Estado adote políticas públicas capazes de ampliar o acesso aos serviços de saúde, e para tal adoção é necessário o elemento financeiro.

Como há uma escassez de recursos e muitas necessidades em cumprir tarefas da sociedade, deve haver uma escolha pelo Estado, baseada na Constituição Federal. Sabe-se que a concretização do Direito Fundamental à Saúde, não é tarefa fácil, justamente por faltar recursos. Entretanto não significa que seja impossível, pelo contrário é perfeitamente possível, basta que o administrador público se esforce na implementação de políticas públicas de efetivação, elegendo tal Direito como prioridade.

Havendo uma ponderação de interesses, o Direito deverá sempre prevalecer em detrimento de outros que não tem o mesmo grau de essencialidade deste Direito Fundamental, isto porque, o Direito a Saúde, está intimamente ligado à vida, bem maior da Constituição Federal de 1988.

O Direito à Saúde além de fundamental é exigível, cabendo ao poder judiciário intervir nos casos em que esse Direito esteja na iminência de sofrer grave lesão, por omissão do Poder Público, como nos casos, de cidadãos que dependem de uma cirurgia para sobreviver e não consegue realizar no Sistema Único de Saúde, neste casos cabe ao Poder Judiciário obrigar mediante mediadas coercitivas o Estado a fornecer ao cidadão prestação estatal que ele necessita, sob pena de descumprir o preceito fundamental e lesionar gravemente o bem maior que é a vida.

Diante de todo exposto, infere-se que apesar de importante a intervenção do Estado este não poderá assumir a função do Poder Executivo, sob pena do ativismo exacerbado ferir o Princípio da Repartição de Poderes. É do Estado a obrigação estatal de fornecer ao cidadão prestações positivas ao cidadão, cabendo ao Poder Judiciário apenas interferir nos casos de em que haja um flagrante desrespeito ao Direito Constitucional à Saúde.

\section{Bibliografia}

Amaral, Gustavo. Direito, escassez e escolha: em busca de critérios jurídicos para lidar com a escassez de recursos e as decisões trágicas. Rio de Janeiro: Renovar, 2001. 
Barletta, Fabiana Rodrigues. O direito à saúde da pessoa idosa. São Paulo: Saraiva, 2010.

Barroso, Luís Roberto. Apontamentos sobre as agências reguladoras. In: MoRAES, Alexandre de (coord.). Agências reguladoras. São Paulo: Atlas, 2002.

Bonavides, Paulo. Curso de direito constitucional. 18. ed. São Paulo: Malheiros, 2006.

Carvalho, Luciana Jordão da Motta Armiliato de. Sobre a política de dispensação de medicamentos no Brasil: mínimo necessário para a efetivação do direito à saúde. Revista de Direito Social. n. 29. ano 8. Sapucaia do Sul: Notadez, jan.-mar. 2008.

Ceconello, Douglas. Sistema de saúde se tornou judicializado. Diário da Justiça/ RS. Porto Alegre, 24.08.2004.

Jorge Neto, Nagibe de Melo. O controle jurisdicional das políticas públicas: concretizando a democracia e os direitos sociais. Salvador: JusPodivm, 2008.

Krell, Andreas J. Direitos sociais e controle judicial no Brasil e na Alemanha: os descaminhos de um direito constitucional "comparado". Porto Alegre: Fabris, 2002.

MÂNICA, Fernando Borges. Racionalidade jurídica e racionalidade econômica na Constituição de 1988. A \& C. Revista de Direito Administrativo e Constitucional. vol. 8. n. 32. Belo Horizonte: A \& C., abr. 2008.

Mota, Ana Elizabeth; Bravo, Maria Inês de Souza; UchôA, Roberta; Nogueira, Vera; Marsiglia, Regina; Gomes, Luciano; Teixeira, Marlene (orgs.). Serviço social e saúde: formação e trabalho profissional. 2. ed. São Paulo: OPAS/OMS/ Ministário da Saúde, 2007.

SARlet, Ingo Wolfgang. A eficácia dos direitos fundamentais. Porto Alegre: Livraria do Advogado, 2002.

Schwartz, Germano. Direito à saúde: efetivação em uma perspectiva sistêmica. Porto Alegre: Livraria do Advogado, 2001.

Silva, José Afonso da. Curso de direito constitucional positivo. 27. ed. São Paulo: Malheiros, 2003.

TORRES, Ricardo Lobo. O direito ao mínimo existencial. Rio de Janeiro: Renovar, 2009.

WeIs, Carlos. Direitos humanos contemporâneos. São Paulo: Saraiva, 2006. 


\section{Pesouisas do Editorial}

\section{Veja também Doutrina}

- Algumas considerações sobre o direito fundamental à proteção e promoção da saúde aos 20 anos da Constituição Federal de 1988, de Ingo Wolfgang Sarlet e Mariana Filchtiner Figueiredo - RDC 67/125;

- Aspectos processuais do acesso a medicamentos e tratamentos médicos: tutela judicial do direito fundamental à saúde, de Marco Aurélio Serau Junior - RT902/66;

- Controle jurisdicional das políticas públicas mínimo existencial e demais direitos fundamentais imediatamente judicializáveis, de Kazuo Watanabe - RePro 193/13;

- Direitos fundamentais e processo o direito à proteção e promoção da saúde entre tutela individual e transindividual, de Ingo Wolfgang Sarlet - RePro 199/13;

- Limitações processuais à tutela judicial do direito à saúde, de Jader Ferreira Guimarães e Wilson José Witzel - RePro 179/217;

- 0 controle de políticas públicas pelo Poder Judiciário, de Ada Pellegrini Grinover - RDB 42/11;

- O Poder Judiciário e as políticas públicas no Brasil: análise doutrinária e evolução casuistica, de Rafael Barreto Garcia - RT879/62; e

- Uma análise da política de saúde brasileira pós-Constituição de 1988, de Eduardo Ribeiro Moreira - RDCl 76/219. 